Piekarska Malgorzata, Maksymowicz Marcela, Kasperski Radosław, Pikulicka Agata, Pacek Katarzyna. The correlation between vitamin D and autoimmune thyroid function - short review. Journal of Education, Health and Sport. 2021;11(9):401-408. eISSN 23918306. DOI http://dx.doi.org/10.12775/JEHS.2021.11.09.051

https://apcz.umk.pl/JEHS/article/view/JEHS.2021.11.09.051

https://zenodo.org/record/5520088

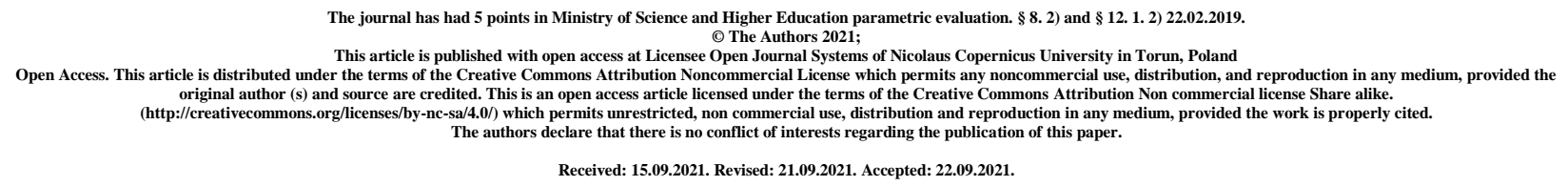

\title{
The correlation between vitamin D and autoimmune thyroid function - short review
}

\section{Małgorzata Piekarska $^{1}$, Marcela Maksymowicz ${ }^{1}$, Radosław Kasperski ${ }^{1}$, Agata Pikulicka ${ }^{1}$, Katarzyna Pacek ${ }^{1}$}

Małgorzata Piekarska ${ }^{1}$, ORCID: 0000-0001-5055-4923, piekarska13@ gmail.com

Marcela Maksymowicz ${ }^{1}$, ORCID: 0000-0003-2611-1609, marcela.maksymowicz@gmail.com

Radosław Kasperski ${ }^{1}$, ORCID: 0000-0002-7364-3205, r.kasperski95@gmail.com

Agata Pikulicka ${ }^{1}$, ORCID: 0000-0003-1693-8127, agapikulicka@gmail.com

Katarzyna Pacek ${ }^{1}$, ORCID: 0000-0001-6947-558X , kasia.pacek1@ gmail.com

${ }^{1}$ Student Scientific Association at the Department of Endocrinology of the Medical University of Lublin, Poland

\begin{abstract}
Vitamin D is traditionally associated with the regulation of mineral metabolism and bone homeostasis, and its deficiency is the cause of diseases such as osteoporosis or osteomalacia. However, numerous studies in recent years suggest that thanks to the common expression of the vitamin D receptor (VDR) on the cells of the body and the related additional anti-inflammatory, immunomodulating, antioxidant, anti-fibrotic vitamin $\mathrm{D}$ effects, it may play a role in the development and progress of autoimmune diseases and tumors. The collected data suggest that low vitamin D levels correlate with the occurrence of autoimmune diseases of the thyroid gland and that there is a significant correlation between $25(\mathrm{OH}) \mathrm{D}$ and anti-TPO or anti-Tg levels. However, these data are inconclusive and further research is needed to confirm this relationship and determine whether lowered vitamin D titer is the cause or rather the consequence of autoimmune thyroid disorders, and whether vitamin D supplementation could prove to be an effective prophylaxis and treatment.
\end{abstract}

Keywords: vitamin D, autoimmune thyroid disease, Graves' disease, Hashimoto's disease 


\section{Introduction and purpose}

Vitamin D, which does not meet all the criteria of a vitamin, is in fact a pleiotropic steroid hormone, with endocrine and paracrine actions [1]. The main function of the active form of vitamin D is to maintain calcium-phosphate and bone homeostasis, e.g. participation in bone growth by supporting the mineralization of the collagen matrix [2]. The discovery of the expression of the vitamin D receptor (VDR) in the 1970s on other cells and tissues of the body (including cancer cells) allowed, however, to draw a conclusion about its numerous extraskeletal effects [3]. Recent studies show that it influences the onset of autoimmune diseases, metabolic syndromes, infections, cardiovascular diseases and cancer [4]. The aim of this review is to collect and summarize the latest reports in the literature on the relationship between vitamin D levels and the functioning and occurrence of autoimmune diseases of the thyroid gland, and the possibilities of using vitamin D supplementation in the treatment of autoimmune thyroid diseases.

\section{Vitamin D - structure, role, mechanisms of action}

Vitamin D comes in two forms. The D2 (ergocalciferol) form is synthesized by fungi and plants, its only source for humans is food, while the D3 (cholecalciferol) form is supplied both with food (its source is e.g. fatty fishes) and it is synthesized by the skin in contact with UVB radiation through the action of 7-dehydrocholesterol reductase. The further metabolism of both forms (Fig. 1) is the same and consists in transport to the liver and hydroxylation to 25-(OH)-D3 (calcidiol), which is the main circulating and storage form of vitamin D and reflects most accurate the actual level of vitamin $\mathrm{D}$ in the body [5]. The active form is produced only in the next step of hydroxylation to 1,25- $(\mathrm{OH}) 2-\mathrm{D} 3$ (calcitriol) by $1-\alpha$-hydroxylase (CYP27B1), which takes place mainly in the kidneys [6]. The process of converting the inactive form into the active one, however, takes place in many other types of cells (including immunological cells), which also express 1- $\alpha$-hydroxylase. The difference is that their activation is not inhibited by parathyroid hormone, high calcitriol and fibroblast growth factor 23 (FGF-23) levels and stimulated by 24-hydroxylase (CYP24A1) which takes place in kidney cells [7]. Vitamin D is stored in adipose cells; after being released from fat, more than $80 \%$ of both forms are bound to vitamin $\mathrm{D}$ binding protein (DBP), and 12-15\% to albumin [5]. 1,25-(OH)2-D3 exerts its modulating effects on cells by binding to the VDR receptor [8]. Thus, directly or indirectly, 1,25dihydroxyvitamin D can control more than 200 genes, including genes responsible for the regulation of cellular proliferation, differentiation, apoptosis, and angiogenesis [9]. 
Fig. 1 Vitamin D metabolism.

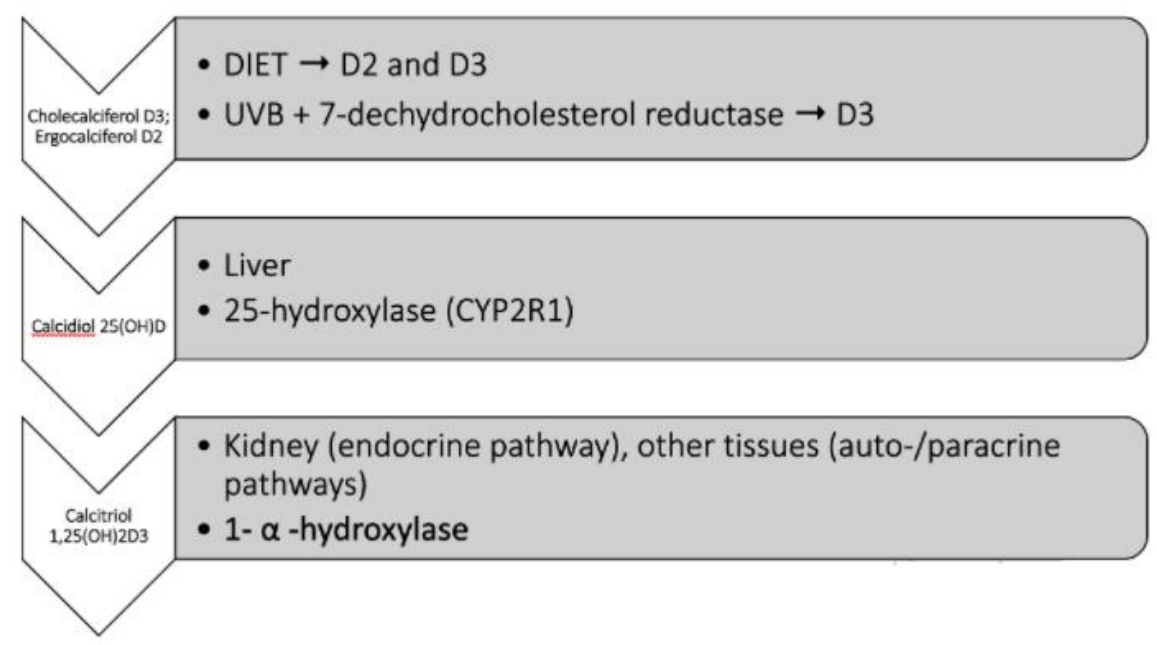

\section{Vitamin D and effect on immune system}

All immune system cells, including macrophages, dendritic cells (DCs), T and B cells express the VDR and CYP27B1 and are therefore susceptible to calcitriol-mediated modulation [10]. Vitamin D affects both types of immunity: it enhances the innate immune response, while it modulates and inhibits the acquired immune response [11,12]. According to numerous reports, vitamin D enhances DCs tolerogenic status by inhibiting differentiation, activation, survival and maturation of DCs, reducing the production of proinflammatory factors such as IL6, IL-12, IL-23 and TNF- $\alpha$, increasing the production of anti-inflammatory interleukins (IL-8, IL-10), and downreulating the surface expression of major histocompatibility complex class I and II and surface costimulatory molecules (CD40, CD80, CD83, CD86) [13]. In addition, calcitriol promotes $\mathrm{B}$ cells apoptosis, preventing their proliferation and differentiation into plasma cells [14], immunoglobulin secretion ( $\operatorname{IgG}$ and $\operatorname{IgM}$ ), and inhibits T-cell proliferation, restricts Th1and Th17-response on account of enhancing the Th2-phenotype response and finally it induces regulatory $\mathrm{T}$ lymphocytes (Treg) $[15,16]$. These multiple mechanisms of vitamin $\mathrm{D}$ action lead to an increase in immune tolerance, which could have potential benefits in the treatment of autoimmune diseases.

A summary of the effect of vitamin D on the immune cells is presented in the table below (Tab.1.). 
Tab. 1. Vitamin D modulating effect on various groups of immune cells.

\begin{tabular}{|c|c|}
\hline Type of the immune cell & The effect of vitamin D \\
\hline Dendritic cell & $\begin{array}{ll}\text { - } & \text { Decreased expression of MHC-I and } \\
& \text { MHC-II,CD40, CD80, CD83, CD86 } \\
\text { - } & \text { Reduced TNF- } \alpha, \text { IL6, IL-12 and IL-23 } \\
& \text { secretion } \\
\text { - } & \text { Increase of IL-8, IL-10 secretion }\end{array}$ \\
\hline B-Lymphocyte & $\begin{array}{l}\text { Decrease of proliferation, } \\
\text { differentation, IgG and IgM synthesis }\end{array}$ \\
\hline T-lymphocyte & $\begin{array}{l}\text { - Limitation of inflammatory Th1- and } \\
\text { Th17-response } \\
\text { - Shift towards anti-inflammatory Th2- } \\
\text { phenotype } \\
\text { - Induction of regulatory T lymphocytes } \\
\text { (Treg) }\end{array}$ \\
\hline
\end{tabular}

\section{Vitamin D and autoimmune thyroid diseases - state of knowledge}

Autoimmune thyroid diseases (AITD) are the most common autoimmune diseases (AID), affecting about 5\% of the population [17]. In both Graves' Disease (GD) and Hashimoto thyroiditis (HT) there is specific lymphocytic infiltration of the thyroid parenchyma [18]. HT is characterized by infiltration of $\mathrm{B}$ and $\mathrm{T}$ lymphocytes (with $\mathrm{CD} 4+$ type $1 \mathrm{~T}$ helper subtype dominance), the presence of anti-thyroid peroxidase (anti-TPO) and/or anti-thyreoglobulin (anti$\mathrm{Tg}$ ) antibodies in the serum, diffuse goiter and dominant hypothyroidism. In GD there is a prevalence of $\mathrm{CD} 4+$ type $2 \mathrm{~T}$ helper subtype cells in infiltration, the infiltrate is mild, and there is a humoral response against TSH receptor (TSHR) with the production of antibodies stimulating the function of follicular cells and leading to hyperthyroidism [19]. As for other autoimmune disorders, also AITD seem to be influenced and induced by the synergy of genetic (i.e thyroidspecific an immunoreulatory genes), environmental (i.e stress, selenium, iodine, cigarette smoking) and existential factors (sex, parity, etc.) [20, 21]. In recent years, numerous studies have been conducted on the possibilities of using the properties of vitamin D promoting immune tolerance in the treatment of AITD. 


\section{Human studies}

Most of clinical studies tend to support the existance of an association between calcitriol deficiency and thyroid autoimmunity, with the proviso that the correlation in HT is more distinct than in GD [18]. The first observational study was published by Goswami et al. in 2009 and demonstrated an inverse correlation between serum vitamin D levels and anti-TPO titres, suggesting the involvement of vitamin D in pathogenesis of AITD [22]. Later, similar results were obtained by Shin et al. by analyzing a group of 111 patients with AITD and 193 non-AITD patients $(r=-0.252 ; p<0.001)$ [23]. The negative correlation between $25(\mathrm{OH}) \mathrm{D}_{3}$ and anti-TPO antibodies was also confirmed in the study by Muscogiuri et al., on a group of 168 older subjects ( $\mathrm{r}=-0.27 ; \mathrm{p}=0.03$ ) [24] and by Camurdan et al., on a group of 152 children (78 recently diagnosed HT, 74 controls) [25].

Unal and coworkers not only proved the above correlation between lower serum $25(\mathrm{OH}) \mathrm{D}$ values and an increase anti-TPO, but also additionally demonstrated an inverse correlation with anti-Tg antibodies in these patients [26]. Another study also reported that prevalence of vitamin D deficiency was higher in patients with AITD compared to age- and sexmatched healthy patients, namely Kivity et al. 2011 [27], Tamer et al. 2011 [28], Bozkurt et al. 2013 [29], Mansournia et al. 2014 [23], Shin et al. 2014 [30], Camurdan et al. 2012 [25].

Furthermore, Tokić et al. focused on the effects of vitamin D on inflammatory status in AITD and proved that in the group of people with HT (45 patients) VDR transcriptional levels were lower than in the healthy controls group (13 people), which was associated with abnormal peripheral mRNA expression in T cells in the first group of patients [31]. In turn, Botelho et al. observed that in patients with low calcidiol levels there was a positive correlation with the level of interleukins TNF- $\alpha$, IL-17, IL-5, and inverse correlation with IL-2 [32].

It is worth mentioning that the positive effect on thyroid function and the related economic benefits were confirmed by the study of Mirhosseini et al. on a group of 11,017 participants who were supplemented with vitamin D to obtain its physiological concentration [33]. Researchers from the Medical University of Warsaw came to very similar conclusion; after analyzing the results of 269 cases (with an additional criterion for dividing into smokers and non-smokers) they showed that non-smoking patients with GD receiving vitamine $\mathrm{D}$ were more likely to achieve immunological remission than those without vitamine D supplementation, especially smokers [34]. However, these results, are not unequivocal, and many publications do not confirm the occurrence of the above correlations.

Mangaraj et al. in the study of 84 patients with new onset Graves' disease observed no correlation between vitamin D and thyroid hormones, thyroid volume, or TRAb titers in Graves' disease [35]. Moreover, Cho et al. demonstrated that daily supplementation of vitamin D has no beneficial effect on the recurrence of Graves' disease in the study of 210 subjects with Graves' disease and vitamin D deficiency, who were followed for at least one year after anti-thyroid drug (ATD) discontinuation [36]. 
Ke et al. did not find a relationship between vitamin $\mathrm{D}$ level and the presence or absence of Hashimoto's thyroiditis in his study participants (51 GD patients, 51 controls) [37], while D'Aurizio et al. showed even higher levels of $25(\mathrm{OH}) \mathrm{D}$ in the group of healthy patients (126 controls) than in the group of patients with AITD (49 GD and 42 HT) [12].

\section{Summary}

Although many studies have shown a relationship between vitamin D levels and AITD, this correlation still remains unclear due to conflicting results from many studies. It also remains to be clarified whether the relationship is modified by such characteristics as race, age, gender, etc. of patients; whether it is vitamin D deficiency that is the cause of hypothyroidism or whether hypothyroidism is associated with a reduction in vitamin D levels, and most importantly whether despite its numerous properties of vitamin $\mathrm{D}$ is such a strong modulator that its supplementation could prove effective in the treatment and prevention of autoimmune diseases of the thyroid gland. More research is needed to unambiguously answer these questions.

\section{References}

[1] Gallo D, Piantanida E, Badino P, Mortara L. The story of a vitamin for bone health that upgraded to hormone for systemic good health. Medicina Historica. 2018;2(3),152-160.

[2] Aranow C. Vitamin D and the immune system. J Investig Med. 2011 Aug;59(6):881-6.

[3] Gallo D, Mortara L, Gariboldi MB, Cattaneo SAM, Rosetti S, Gentile L, Noonan DM, Premoli P, Cusini C, Tanda ML, Bartalena L, Piantanida E. Immunomodulatory effect of vitamin $\mathrm{D}$ and its potential role in the prevention and treatment of thyroid autoimmunity: a narrative review. J Endocrinol Invest. 2020 Apr;43(4):413-429.

[4] Makariou S, Liberopoulos EN, Elisaf M, Challa A. Novel roles of vitamin D in disease: what is new in 2011? Eur J Intern Med. 2011 Aug;22(4):355-62.

[5] Kmieć P, Sworczak K. Vitamin D in thyroid disorders. Exp Clin Endocrinol Diabetes. 2015 Jul;123(7):386-93.

[6] Nettore IC, Albano L, Ungaro P, Colao A, Macchia PE. Sunshine vitamin and thyroid. Rev Endocr Metab Disord. 2017 Sep;18(3):347-354.

[7] Prietl B, Treiber G, Pieber TR, Amrein K. Vitamin D and immune function. Nutrients. 2013 Jul 5;5(7):2502-21.

[8] Illescas-Montes R, Melguizo-Rodríguez L, Ruiz C, Costela-Ruiz VJ. Vitamin D and autoimmune diseases. Life Sci. 2019 Sep 15;233:116744.

[9] Holick MF (2007) Vitamin D deficiency. N Engl J Med. 357(3):266-281

[10] Colotta F, Jansson B, Bonelli F. Modulation of inflammatory and immune responses by vitamin D. J Autoimmun. 2017 Dec;85:78-97.

[11] Rosen Y, Daich J, Soliman I, Brathwaite E, Shoenfeld Y. Vitamin D and autoimmunity. Scand J Rheumatol. 2016 Nov;45(6):439-447.

[12] D'Aurizio F, Villalta D, Metus P, Doretto P, Tozzoli R. Is vitamin D a player or not in the pathophysiology of autoimmune thyroid diseases? Autoimmun Rev. 2015 May;14(5):363-9. 
[13] Barragan M, Good M, Kolls JK. Regulation of Dendritic Cell Function by Vitamin D. Nutrients. 2015 Sep 21;7(9):8127-51.

[14] Drozdenko, G.; Scheel, T.; Heine, G.; Baumgrass, R.; Worm, M. Impaired T cell activation and cytokine production by calcitriol-primed human B cells. Clin. Exp. Immunol. 2014, 178, 364-372.

[15] Bizzaro G, Shoenfeld Y. Vitamin D and thyroid autoimmune diseases: the known and the obscure. Immunol Res. 2015 Feb;61(1-2):107-9.

[16] Koehler VF, Filmann N, Mann WA. Vitamin D Status and Thyroid Autoantibodies in Autoimmune Thyroiditis. Horm Metab Res. 2019 Dec;51(12):792-797.

[17] Orgiazzi J. Thyroid autoimmunity. Presse Med. 2012 Dec;41(12 P 2):e611-25.

[18] Vieira IH, Rodrigues D, Paiva I. Vitamin D and Autoimmune Thyroid Disease-Cause, Consequence, or a Vicious Cycle? Nutrients. 2020 Sep 11;12(9):2791.

[19] Klecha AJ, Barreiro Arcos ML, Frick L, Genaro AM, Cremaschi G. Immune-endocrine interactions in autoimmune thyroid diseases. Neuroimmunomodulation. 2008;15(1):68-75.

[20] Antonelli A, Ferrari SM, Corrado A, Di Domenicantonio A, Fallahi P. Autoimmune thyroid disorders. Autoimmun Rev. 2015 Feb;14(2):174-80.

[21] Effraimidis G, Wiersinga WM. Mechanisms in endocrinology: autoimmune thyroid disease: old and new players. Eur J Endocrinol. 2014 Jun;170(6):R241-52.

[22] Goswami R, Marwaha RK, Gupta N, Tandon N, Sreenivas V, Tomar N, Ray D, Kanwar R, Agarwal R. Prevalence of vitamin D deficiency and its relationship with thyroid autoimmunity in Asian Indians: a community-based survey. Br J Nutr. 2009 Aug;102(3):382-6.

[23] Mansournia N, Mansournia MA, Saeedi S, Dehghan J. The association between serum 25OHD levels and hypothyroid Hashimoto's thyroiditis. J Endocrinol Invest. 2014 May;37(5):473-6.

[24] Muscogiuri G, Mari D, Prolo S, Fatti LM, Cantone MC, Garagnani P, Arosio B, Di Somma C, Vitale G. 25 Hydroxyvitamin D Deficiency and Its Relationship to Autoimmune Thyroid Disease in the Elderly. Int J Environ Res Public Health. 2016 Aug 26;13(9):850.

[25] Camurdan OM, Döğer E, Bideci A, Celik N, Cinaz P. Vitamin D status in children with Hashimoto thyroiditis. J Pediatr Endocrinol Metab. 2012;25(5-6):467-70.

[26] Unal AD, Tarcin O, Parildar H, Cigerli O, Eroglu H, Demirag NG. Vitamin D deficiency is related to thyroid antibodies in autoimmune thyroiditis. Cent Eur J Immunol. 2014;39(4):493-7.

[27] Kivity S, Agmon-Levin N, Zisappl M, Shapira Y, Nagy EV, Dankó K, Szekanecz Z, Langevitz P, Shoenfeld Y. Vitamin D and autoimmune thyroid diseases. Cell Mol Immunol. 2011 May;8(3):243-7.

[28] Tamer G, Arik S, Tamer I, Coksert D. Relative vitamin D insufficiency in Hashimoto's thyroiditis. Thyroid. 2011 Aug;21(8):891-6.

[29] Bozkurt NC, Karbek B, Ucan B, Sahin M, Cakal E, Ozbek M, Delibasi T. The association between severity of vitamin D deficiency and Hashimoto's thyroiditis. Endocr Pract. 2013 MayJun;19(3):479-84. 
[30] Shin DY, Kim KJ, Kim D, Hwang S, Lee EJ. Low serum vitamin D is associated with antithyroid peroxidase antibody in autoimmune thyroiditis. Yonsei Med J. 2014 Mar;55(2):476-81. [31] Tokić S, Štefanić M, Karner I, Glavaš-Obrovac L. Altered expression of CTLA-4, CD28, VDR, and CD45 mRNA in T cells of patients with Hashimoto's thyroiditis - a pilot study. Endokrynol Pol. 2017;68(3):274-828.

[32] Botelho IMB, Moura Neto A, Silva CA, Tambascia MA, Alegre SM, Zantut-Wittmann DE. Vitamin D in Hashimoto's thyroiditis and its relationship with thyroid function and inflammatory status. Endocr J. 2018 Oct 29;65(10):1029-1037.

[33] Mirhosseini N, Brunel L, Muscogiuri G, Kimball S. Physiological serum 25hydroxyvitamin D concentrations are associated with improved thyroid function-observations from a community-based program. Endocrine. 2017 Dec;58(3):563-573.

[34] Płazińska MT, Czarnywojtek A, Sawicka-Gutaj N, Zgorzalewicz-Stachowiak M, Czarnocka B, Gut P, Karlinska M, Fichna M, Stachowski A, Ruchała M, Krela-Kaźmierczak I, Królicki L. Vitamin D deficiency and thyroid autoantibody fluctuations in patients with Graves' disease - A mere coincidence or a real relationship? Adv Med Sci. 2020 Mar;65(1):39-45.

[35] Mangaraj S, Choudhury AK, Swain BM, Sarangi PK, Mohanty BK, Baliarsinha AK. Evaluation of Vitamin D Status and its Impact on Thyroid Related Parameters in New Onset Graves' Disease- A Cross-sectional Observational Study. Indian J Endocrinol Metab. 2019;23(1):35-39.

[36] Cho YY, Chung YJ. Vitamin D supplementation does not prevent the recurrence of Graves' disease. Sci Rep. 2020;10(1):16.

[37] Ke W, Sun T, Zhang Y, He L, Wu Q, Liu J, Zha B. 25-Hydroxyvitamin D serum level in Hashimoto's thyroiditis, but not Graves' disease is relatively deficient. Endocr J. 2017 Jun 29;64(6):581-587. 